\title{
Research and Test Analysis on the Construction of Motion Cooperative System Based on B/S Mode
}

\author{
Yongxin Wang ${ }^{1}$ and Qiufen Wang ${ }^{2, *}$ \\ ${ }^{I}$ Nanyang Institute of Technology/Department of Physical Education, Nanyang Henan, 473004, China; ${ }^{2}$ Nanyang Insti- \\ tute of Technology/College of Computer and Information Enginerring, Nanyang Henan, 473004, China
}

\begin{abstract}
The network teaching system is composed of several interrelated parts and can carry out effective and reliable collaborative work based on a certain framework. To explore the effects of computer-supported collaborative learning on sports and improve students' physical learning efficiency, the author constructed a sports collaborative learning system based on the B / S model and experimentally studied the teaching effect of the system. The experimental findings demonstrated that, computer-supported collaborative learning of sports can effectively improve students' interest in learning sports, which is conductive to enhance the learning attitude and objectives which is significantly superior to the traditional sports teaching methods in terms of evaluating the technical movements.
\end{abstract}

Keywords: Collaborative learning, Computer, Sports, B/S Model, Teacher module, Student module, Energy supply design.

\section{INTRODUCTION}

Sports can be tricky and have a complex structure. It is somewhat difficult for teachers to make demonstrations, therefore, using multimedia-aided teaching can produce a good teaching effect [1]. Traditional physical education is carried out in an open and large space, where students canexpand their sphere of activities and have access to diversified field equipment [2-5]. Mainly, physical education is provided by teachers through orally given lectures, supplemented with action modeling, student imitation and independent practice. In contrast, collaborative learning is a learning model more capable of mobilizing the learning initiative and enthusiasm of students, and helps them cultivate students' collaboration spirit and lifelong sport consciousness $[6,7]$. The author studied computer-supported collaborative learning of sports. On the basis of constructing the collaborative learning system, experimental research is implemented to evaluate the effect of computer-supported collaborative learning of sports.

\section{RELATED THEORY RESEARCH OF COLLABO- RATIVE LEARNING}

\subsection{Collaborative Learning}

Professor Slavin (the USA), a representative figure of collaborative learning research, believes that collaborative learning is a kind of classroom technology, where students carry out learning activities in small groups and win recognition or awards according to the group's achievement. Domestic scholars define collaborative learning as all relevant correlation behaviors concerning mutual aid and cooperation,

*Address correspondence to this author at the Nanyang Institute of Technology/College of Computer and Information Engineering, Nanyang Henan, 473004, China; Tel: 15838482302; E-mail:w_qiufen@163.com undertaken by study members who participate in groups to ultimately achieve the maximum learning outcomes and acquire common learning objectives. At present, there is little research available regarding sports collaborative learning. Findings report how to apply collaborative learning in sports classes while neglecting the realization of computersupported collaborative learning of sports [8-11]. Computersupported collaborative learning is a flexible learning mode that can both be executed for both individual learning and small group learning. Computer-supported collaborative learning is non-simultaneous in time, and thus it has become the key form of vocational training, lifelong learning and correspondence education. The studies on computersupported collaborative learning started early abroad. Currently, a lot of research softwares have been developed and published, such as FirstClass, Blackboard, and WebCT. Research on computer-supported collaborative learning started relatively late in our country, and at present, Chin has the WebCL collaborative learning platform devised by Beijing Normal University. These collaborative learning platforms are for universal use. However, targeted and systematic development has not been observed in sports collaborative learning yet.

\subsection{Computer-Supported Collaborative Learning of Sports}

Physical education is a cognitive activity in which students feel, think and memorize, and it is also a sport cognitive activity. Factors influencing sports cognition encompass learning motivation, innate ability, past experiences and learning phrases, while these factors also have an impact on action learning. Accordingly, in the teaching process, teachers need to stimulate a sense of accomplishment in students and enhance their self-esteem with their learning abilities, to meet both their spiritual and physical needs. Because there are differences in students with respect to physical qualities, 
perception and athletic abilities, some students find it difficult to perceive action concepts due to lack of specific experience and appropriate guidance. Computer-supported collaborative learning of sports provides intuitive assisted learning through online learning and multimedia-assisted learning experience, so that students can get stimulation and guidance of action learning at various stages and have an accurate response. Today, with the rapid development of computer network technology and multimedia technology, education modes have become more open and diversified. Together with the system applications such as distance education, computer-supported collaborative learning of sports can more effectively achieve sports cognition and action learning.

\subsection{Evaluation of Learning Effect}

The concept of education evaluation is usually expressed in an equation, namely:

Evaluation $=$ Measurement (amount of account) Or non measurement (qualitative description) + The value judgment (1)

The evaluation methods of computer-supported collaborative learning include analytic hierarchy process (AHP) and scalable evaluation. The definition of scalable evaluation includes four aspects, which are matter-element; classical domain, joint domain and matter-element to be evaluated; distance, correlation function with relational degree and evaluation criteria.

\subsubsection{Matter-Element}

By considering a thing $\mathrm{Q}$, wherein the magnitude of its feature $\mathrm{c}$ is set as $\mathrm{v}, \mathrm{R}=(\mathrm{Q}, \mathrm{c}, \mathrm{v})$ is used to indicate the basic elements of things, namely matter-element. If there are $n$ features in a thing, then the matter-element of $Q$ can be expressed as:

$$
R=\left[\begin{array}{ccc}
c_{1} & v_{1} \\
Q, & c_{2} & v_{2} \\
\vdots & \vdots \\
c_{n} & v_{n}
\end{array}\right] \text {, where } \mathrm{R} \text { is an n-dimensional }
$$

matter-element.

\subsubsection{Classical Domain, Joint Domain and Matter-element to be Evaluated}

If there are $m$ quality grades of evaluation, $m$ things can be expressed. $\mathrm{y}_{\mathrm{ij}}$ is used to express the magnitude domain (which is the classical domain) of the evaluation index $c_{j}$ for $\mathrm{Q}_{\mathrm{i}}$, corresponding to the evaluation grade $\mathrm{i}$. A matter-element of $m$ things can be developed:

$$
R=\left[\begin{array}{ccc}
c_{1} & v_{1} \\
Q, & c_{2} & v_{2} \\
\vdots & \vdots \\
c_{n} & v_{n}
\end{array}\right]=\left[\begin{array}{cc}
y_{i 1} & \left\langle a_{i 1}, b_{i 1}\right\rangle \\
y_{i 2} & \left\langle a_{i 2}, b_{i 2}\right\rangle \\
\vdots & \vdots \\
y_{i n} & \left\langle a_{i n}, b_{i n}\right\rangle
\end{array}\right]
$$

For the classical domain, the following matter-element is constructed:

$$
\begin{aligned}
& R_{0}=\left[\begin{array}{cc}
c_{1} & y_{1} \\
Q_{0}, & y_{2} \\
\vdots & \vdots \\
c_{n} & y_{n}
\end{array}\right]=\left[\begin{array}{ccc} 
& & \\
c_{1} & \left\langle a_{p 1}, b_{p 1}\right\rangle \\
c_{2} & \left\langle a_{p 2}, b_{p 2}\right\rangle \\
\vdots & \vdots \\
c_{n} & \left\langle a_{p n}, b_{p n}\right\rangle
\end{array}\right] \\
& y_{p j=}\left\langle a_{p j}, b_{p j}\right\rangle \\
& \rho\left(y, Y_{0}\right)=|y-(a+b) / 2|-(b-a) / 2 \\
& K_{j}\left(y_{i}\right)=\left\{\begin{array}{l}
-\rho\left(y_{i}, Y_{j i}\right) \\
\frac{\left|Y_{j i}\right|}{\rho}, y_{i} \in Y_{j i} \\
\frac{\rho\left(y_{i}, Y_{p i}\right)-\rho\left(y_{i}, Y_{j i}\right)}{\rho\left(y_{i}\right)} y_{i} \notin Y_{j i}
\end{array}\right\} \\
& K_{j}\left(p_{0}\right)=\sum_{i=1}^{n} \lambda K_{j}\left(y_{i}\right)
\end{aligned}
$$

Where $y_{p j=}\left\langle a_{p j}, b_{p j}\right\rangle$ is the joint domain. The matter element to be evaluated can be expressed by the following formula:

$$
R_{0}=\left[\begin{array}{ccc}
c_{1} & y_{1} \\
Q_{0}, & c_{2} & y_{2} \\
\vdots & \vdots \\
& c_{n} & y_{n}
\end{array}\right]
$$

\subsubsection{Distance, Correlation Function and Relational De- gree}

Assuming that $y$ is an arbitrary point in the real domain, and $\mathrm{Y} 0=<\mathrm{a}, \mathrm{b}>$ is an arbitrary interval in the real domain, then the distance between $y$ and $Y_{0}$ is shown as $\rho\left(y, Y_{0}\right)=|y-(a+b) / 2|-(b-a) / 2$. Hence, according to the definition of distance as well as joint domain and classical domain, the correlation function can be obtained as follows:

$$
K_{j}\left(y_{i}\right)=\left\{\begin{array}{l}
\frac{-\rho\left(y_{i}, Y_{j i}\right)}{\left|Y_{j i}\right|}, y_{i} \in Y_{j i} \\
\frac{\rho\left(y_{i}, Y_{j i}\right)}{\rho\left(y_{i}, Y_{p i}\right)-\rho\left(y_{i}, Y_{j i}\right)}, y_{i} \notin Y_{j i}
\end{array}\right\}
$$

And therefore, the relational degree can be expressed as:

$$
K_{j}\left(p_{0}\right)=\sum_{i=1}^{n} \lambda K_{j}\left(y_{i}\right)
$$

\subsubsection{Evaluation criteria}

When the correlation function $\geq 0$, it suggests that the greater the value, the greater the extent to which the evaluation index belongs to the grade standard. When $-1 \leq$ the cor- 


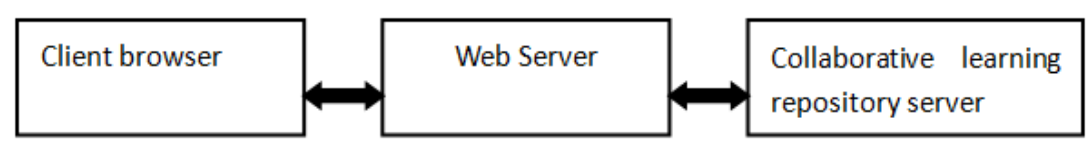

Fig. (1). Online sports collaborative learning system framework based on B/S mode.

relation function $<0$, it suggests that the greater the value, the larger the probability that the evaluation index is transformed into the grade standard. Moreover, when the correlation function $<-1.0$, it implies that the greater the value, the larger the difficulty in transforming the evaluation index into the grade standard.

\section{COMPUTER-SUPPORTED COLLABORATIVE LEARNING SYSTEM OF SPORTS}

The network teaching system is composed of several interrelated parts and can carry out effective and reliable collaborative work through a certain framework, such as arranging learning activities. Common universal-type network teaching system is based on the $\mathrm{B} / \mathrm{S}$ model. This design is constructed grounded on the $\mathrm{B} / \mathrm{S}$ mode supporting online sports collaborative learning system. In the sports collaboration system, the client browser is connected to the Web server and to the collaborative learning repository server by networking to realize asynchronous communications and collaborative learning, as shown in Fig. (1). The system integrates artificial intelligence reasoning and web services functions, in which the repository has strong adaptability. The system can be divided into two forms, synchronous and asynchronous collaborative learning. Learners can carry out collaborative learning at any node through the Web browser and employ collaborative learning tools for synchronous and asynchronous discussions. Moreover, such collaborative learning is not confined by time or location. Through online and offline self-independent learning, students are able to master the basic knowledge, technology, rules and judgment laws of sports, while conducting collaborative learning by in-class groups. The online self-directed learning process can stimulate students' interest in sports, so that students are motivated to learn sports, while building their capacity of learning sports and conductingscientific study.

\section{ENERGY SUPPLY DESIGN AND IMPLEMENTA- TION OF SPORTS COMPUTER-SUPPORTED COL- LABORATIVE LEARNING SYSTEM}

\subsection{Functional Realization Principle and Technology}

ASP belongs to the server-side webpage compilation environment, with which the designed pages can be compiled by the server and sent directly to the client browser, showing a strong portability. Different from other general scripting languages, it does not need to make compilation via the browser on the browser side. ASP is very powerful, easy to write and highly secured, therefore, it is widely used in web development platforms, whereas NT Server in combination with ASP's development environment is not only simple, but also powerful. Therefore, the function design and implementation of the online sports cooperative learning system are attained by ASP in the NT environment. Data interface adopts Microsoft ADO data access technology, which is designed to work collaboratively with OLE DB Provider Data
Access Layer, and thus provides generic data access. ADO belongs to an object of ASP, and therefore ASP can have easy access to the database by ADO. In addition, the design and implementation of system function modules also use video production and acquisition, multimedia courseware production and Authorware technology, etc.

\subsection{Student Module Function Design}

In the student module, students can customize their learning menus and realize asynchronous learning, while also being able to study sports collaboration online, download courseware from the courseware database, carry out interactive sessions of questions and answers, and send e-mails, etc. After logging in successfully, students can select and learn courses in accordance with the customized knowledge list and activity menu. The student module features incorporate five aspects, which are curriculum resources, download of learning resources, online testing, communication and interaction, and curriculum answering module. Curriculum resources provide students with all the project information available to learning, encompassing the key points of teaching, teaching videos, teaching pictures, and electronic courseware, with the facility of downloading learning resources, electronic courseware, online courses, sports video and sports pictures, etc. In online testing, students can assess their understanding of the teaching content through online testing, and can find out their weaknesses for further improvements. Communication and interaction enable students to communicate with other students and also with teachers; in this way students are able to synchronously communicate through the communication and interaction module and leave asynchronous messages, thereby achieving the purpose of learning from each other. In terms of curriculum answering module, students can see a list of related online teachers. After logging in, students can propose real-time questions online. By resolving the problems in a timely manner, students can improve their learning efficiency. Fig. (2) shows computer-supported collaborative learning strategies.

\subsection{Teacher Module Function Design}

Teachers make electronic courseware for sports learning curriculum together with relevant experts, including pictures, video tapes, video and animation. Further, the courseware can be organized as the database courseware and the courseware content should be sufficiently appropriate for the learning content of classroom teaching. At the same time, teachers are also able to answer questions online and store information in the Q \& A database through the course answering module and answer mails. Teachers can view the information in the curriculum resource database, maintain the sports menus, sports knowledge and mentoring data, and manage the curriculum resources in the system. The teacher module features include six parts, which are course menu management, curriculum resources management, student information management, online test management, commu- 


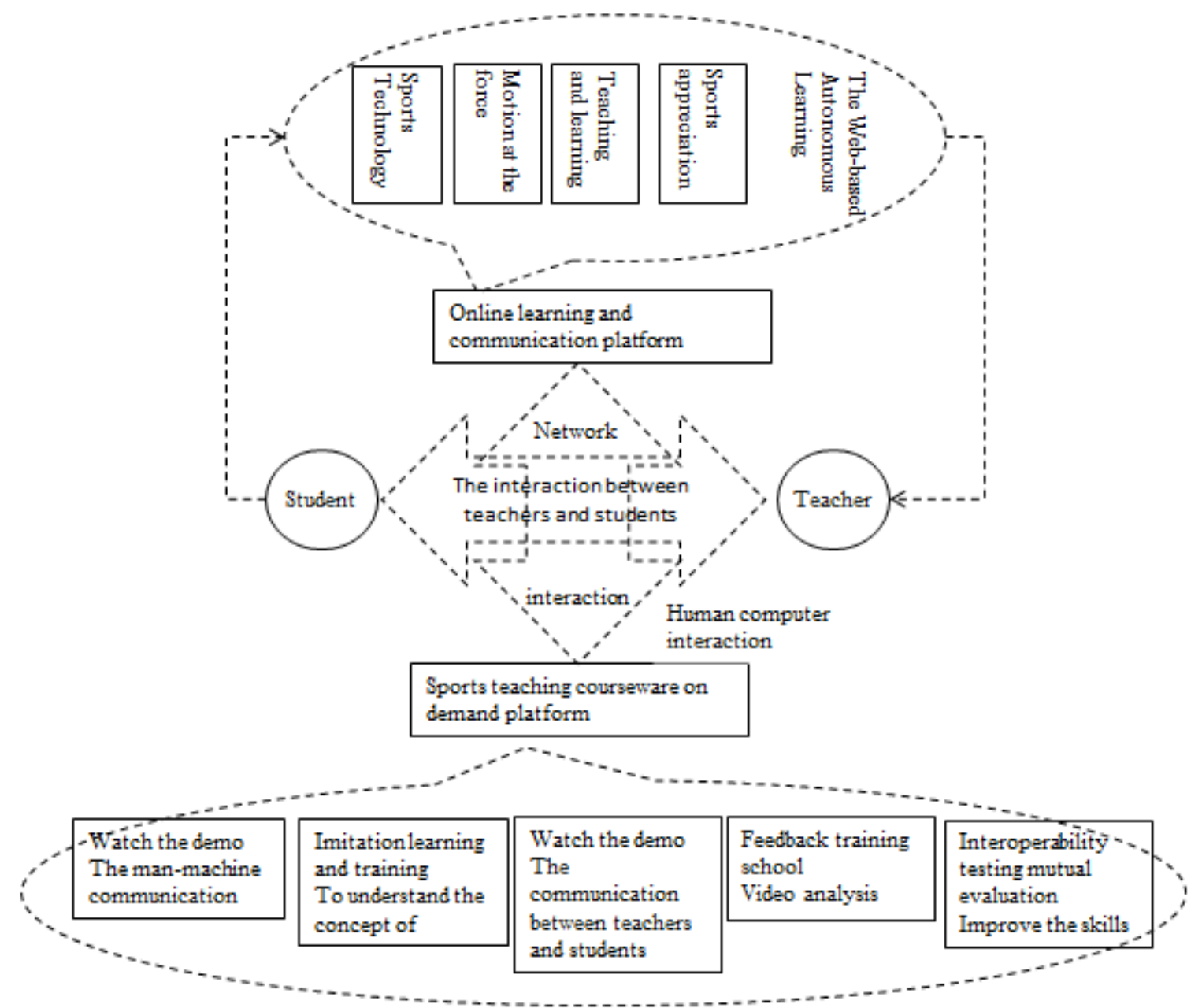

Fig. (2). Computer-supported collaborative learning strategies.

nication and interaction management, and course answering management. Course menu management is meant to devise scientific and reasonable learning content in the physical education curriculum for students. Curriculum resources management comprises uploading and deletion of teaching documents such as instructional videos and animations. For the management of student information, after students are registered, teachers can view and verify students' information through the platform and set permissions for students. With regard to online test management, teachers are responsible for adding and modifying the test subject, and make assessments by students' test results. For the management of communication and interaction, teachers can find out students' interest in learning and the key and difficult points through this module, to perfect the course content by making appropriate changes. With reference to course answering management, teachers can synchronously answer students' questions through the module, while they can also asynchronously answer problems by answering mails.

\section{ANALYSIS OF COMPUTER-SUPPORTED COL- LABORATIVE LEARNING OF SPORTS}

In order to explore the validity of the computer-supported collaborative learning system of sports, the author conducted an experimental study on the research subjects of 100 students of sports.

\subsection{Research Subjects and Methods}

\subsubsection{Research subjects}

There were 100 students of table tennis in sports specialty, who were randomly divided into two groups; the experimental group and the observational group. The experimental group consisted of 50 students, including 40 males and 10 females. The control group also consisted of 50 students, with 42 males and 8 females. Before the experiment, indexes like the height, weight, grip strength, vital capacity, standing long jump, stairs experiment and table tennis service were measured followed by evaluation of all the students. There were significant differences in the indexes between the above two groups of students $(\mathrm{P}>0.05)$, and therefore, two groups of students were comparable.

\subsubsection{Research Methods and Experimental Design}

Research methods: (1) Questionnaire survey: learning interest questionnaires were designed and distributed. The interests in physical education class of two groups of students were analyzed and an exercise attitude scale investigation was made of two groups of students in terms of physical 
Table 1. Comparison of sports learning interest between two groups of students $[\bar{x} \pm s]$.

\begin{tabular}{|c|c|c|c|c|}
\hline & Number of Students & Score & T & P \\
\hline \hline Experimental group & 50 & $47.2 \pm 5.5^{*}$ & 2.40 & 0.018 \\
\hline Control group & 50 & $44.1 \pm 7.3$ & & \\
\hline
\end{tabular}

Table 2. Comparison of scores of target attitudes and emotional experience of two groups of students $[\bar{x} \pm s]$.

\begin{tabular}{|c|c|c|c|c|c|}
\hline & Number of Students & \multicolumn{2}{|c|}{ Target Attitudes } & \multicolumn{2}{c|}{ Emotional Experience } \\
\hline & & $\begin{array}{c}\text { Before Collaborative } \\
\text { Learning }\end{array}$ & $\begin{array}{c}\text { After Collaborative } \\
\text { Learning }\end{array}$ & $\begin{array}{c}\text { Before Collaborative } \\
\text { Learning }\end{array}$ & $\begin{array}{c}\text { After Collaborative } \\
\text { Learning }\end{array}$ \\
\hline \hline Experimental group & 50 & $39.8 \pm 5.7$ & $42.8 \pm 4.8^{* * \# \#}$ & $20.2 \pm 4.1$ & $24.0 \pm 3.8^{* *}$ \\
\hline Control group & 50 & $37.6 \pm 6.2$ & $38.3 \pm 6.4$ & $21.3 \pm 4.3$ & $22.5 \pm 4.7$ \\
\hline
\end{tabular}

exercise attitude (objective attitude, behavior cognition, behavioral habits, and emotional experience). (2) Experimental method: two experiment assumptions were set up. First, the experimental group was superior to the control group in terms of the students' interest in learning and their attitude towards exercise. Moreover, students' learning interest and attitude towards exercise were linked related to computersupported collaborative learning of sports factors. Secondly, the experimental group of the table tennis class was superior to the control group and the students' academic performance was linked related to computer-supported collaborative learning of sports.

Experimental design: The control group was taught by the traditional physical education method, where lectures were given orally by teachers, supplemented with action modeling, student imitation and independent practice. The experimental group experienced computer-supported collaborative learning of sports on the basis of the control group teaching. 50 students in the experimental group were divided into 5 groups, and multimedia teaching and collaborative learning were implemented in small groups to realize human-computer interaction between teachers and students. Multimedia teaching and collaborative learning were carried out in the form of small groups in order to achieve the objective that all group members master the knowledge and action skills. In addition to different teaching methods for two groups of students, the other conditions remained the same, including the instructor, teaching content, test time, test content and methods. The teaching contents included service backhand and forehand, cut up forehand and backhand, parrel truck, basic foot movements, singles and doubles tactics and methods, as well as singles and doubles competition rules and the referee law. The experiment lasted 12 weeks.

\subsubsection{Evaluation Indexes}

Target hitting tests and assessment of technique were conducted in two groups of students. The target hitting tests were conducted to test and evaluate the stability of the technology and for the assessment of technique including technical accuracy, rationality and normative evaluation of stu- dents' movements. It was divided into five grades, A, B, C, $\mathrm{D}$ and $\mathrm{E}$. The grading criteria used Z-points for calculation and conversion into percentage.

\subsubsection{Statistical Analysis}

The data obtained were processed using SPSS17.0 data statistical software. The enumeration data utilization rate was calculated by the chi-square test The measured data were shown in the mean \pm standard deviation. T-test was used, with $\mathrm{P}<0.05$, showing statistically significant differences.

\subsection{Results and Discussions}

It was found from the questionnaire results that the students in the experimental group obtained $(47.2 \pm 5.5)$ points based on their interest in learning sports, while students in the control group earned $(44.1 \pm 7.3)$ points. Apparently, the experimental group scored significantly higher than the control group $(\mathrm{P}=0.018<0.05)$. The survey on the attitude towards exercise discovered that students in the experimental group after collaborative learning scored significantly higher in the objective attitude and emotional experience than after collaborative learning ( $\mathrm{P}<0.01)$, whereas the control group demonstrated no significant differences before and after teaching in terms of their attitude towards exercise. Meanwhile, after collaborative learning, students in the experimental group scored significantly better than the control group with regard to objective attitude $(\mathrm{P}<0.01)$. This suggests that computer-supported collaboration learning of sports is conducive to improving students' interest in learning sports, enhancing their target attitude towards the cultivation of training attitudes to help them acquire sound emotional experience, as shown in Tables $\mathbf{1}$ and $\mathbf{2}$.

There were no significant differences between the experimental group and the control group in the combined technical performance $(\mathrm{P}<0.05)$, which indicated that the experimental factors exerted no impact on the combined technical achievements of table tennis. This is mainly because the experimental teaching process is short while the training of table tennis features involves many technical skills. There- 
fore, it is impossible for students to fully grasp high-quality combined with technical actions in a short time. The service technical performance of the experimental group was significantly superior to the control group ( $\mathrm{P}<0.05)$, suggesting that students who received collaborative learning were more accurate, reasonable and standardized in serving technology. This is mainly because the experimental group achieved the effect of using the superiority to bring along the poor through sports collaborative learning, thus ultimately realizing common progress of the group.

\section{CONCLUSION}

Physical education is characterized by practicality. It involves teaching activities that enhance physical fitness, inculcating sports knowledge, technology and skills. In physical education, intuitional instruction is an intuitive way, by which teachers can carry out physical education through visualized demonstration and explanation. With the rapid development of computer network information, and penetration of extensive contacts among education, society and individuals, education has become more open and diversified, while online education has become the best practice of open education. This paper built a computer-supported collaborative learning of sports system grounded on the B/S structure, and then carried out experimental teaching. It was found from the experimental teaching effects that computer-supported collaborative learning of sports is conducive to effectively improve students' interest in learning sports, correct their target attitude for the cultivation of training attitudes and help them acquire sound emotional experience. Students who received collaborative learning were observed to be more accurate, reasonable and standardized in serving technology, thus ultimately realizing progress of the groups.

\section{CONFLICT OF INTEREST}

The authors confirm that this article content has no conflict of interest.

\section{ACKNOWLEDGEMENTS}

This work is supported by Soft science project of Henan Province (No. 142400411234).

\section{REFERENCES}

[1] Z. Zhuang, W. Huang, and L. Wang, "On the development and prospect of multimedia aided FL learning in China," Cafle Computer-Assisted Foreign Language Education, vol. 1, pp. 002, 2007.

[2] D. Dale, and B. C. Charles, "Physical activity participation of high school graduates following exposure to conceptual or traditional physical education," Research Quarterly for Exercise and Sport, vol. 71, no. 1, pp. 61-68, 2000.

[3] S.M. Jorgenson, J.D. George, C.L. Blakmore, D. Chamberlain, "The efficacy of infusing homework assignments into traditional physical education activity classes," Physical Educator, vol. 58, no. 1 , pp. 14, 2001

[4] D. K. Hagedorn, and E. Holm, "Effects of traditional physical training and visual computer feedback training in frail elderly patients. A randomized intervention study," European Journal of Physical and Rehabilitation Medicine, vol. 46, no. 2, pp. 159-168, 2010.

[5] T. B.J. Browne, B. C. Teresa, and A. H. Peter, "A comparison of rugby seasons presented in traditional and sport education formats," European Physical Education Review, vol. 10, no. 2, pp. 199-214, 2004.

[6] B. Yao, "Research on Role of Learning Organizational Theory to the PE Majors in Teachers College," Software Engineering and Knowledge Engineering: Theory and Practice. Springer Berlin Heidelberg, pp. 611-616, 2012.

[7] Y. Wu, and D. Li, "Deepening the Reform of School Physical Education to Enhance Students' Quality." Engineering Education and Management. Springer Berlin Heidelberg, pp. 699-706, 2012.

[8] S.L. Wang, and S.J. L. Sunny, "The effects of group composition of self-efficacy and collective efficacy on computer-supported collaborative learning," Computers in Human Behavior, vol. 23, no. 5, pp. 2256-2268, 2007.

[9] N. Miyake, "Computer supported collaborative learning," The SAGE Handbook of E-Learning Research, pp. 248-265, 2007.

[10] G. Gay, et al. "The effects of wireless computing in collaborative learning environments," International Journal of Human-Computer Interaction, vol. 13, no. 2, pp. 257-276, 2001.

[11] J. Kimmerle, and C. Ulrike, "Group awareness and self-presentation in computer-supported information exchange," International Journal of Computer-Supported Collaborative Learning, vol. 3, no. 1, pp. 85-97, 2008.

Received: June 10, 2015
(C) Wang and Wang; Licensee Bentham Open.

Revised: July 29, 2015

Accepted: August 15, 2015

This is an open access article licensed under the terms of the (https://creativecommons.org/licenses/by/4.0/legalcode), which permits unrestricted, noncommercial use, distribution and reproduction in any medium, provided the work is properly cited. 